Cataloging \& Classification Vol. 35, No. 3/4, 2003, pp. 491-523

ISSN: (Print 0163-9374) (Online 1544-4554)

doi: 10.1300/J104v35n03_10

(C) 2003 The Haworth Press, Inc. All Rights Reserved

http://www.tandf.co.uk/journals/haworth-journals.asp

http://www.tandf.co.uk/journals/titles/01639374.asp

http://www.informaworld.com/openurl?genre=article \&issn=0163-9374\&volume=35\&issue $=3 \&$ spage $=491$

\title{
Description and Access in Rare Books Cataloging: A Historical Survey
}

\section{Beth M. Russell}

Beth M. Russell, MA, MLIS, is Head, Special Collections Cataloging, The Ohio State University Libraries, Columbus, OH 43210-1286 (E-mail: bethrussell@ osu.edu).

\begin{abstract}
SUMMARY. Rare book cataloging codes and practices have been shaped by a constant interplay between the tradition of descriptive bibliography and the evolution of library cataloging codes. At the same time, technological changes, such as the emergence of bibliographic databases and online catalogs, have led to promises of increased flexibility and usability in records for rare books. This article will focus on the development of modern Anglo-American rare book cataloging, highlighting special access points that often appear to exist outside the mainstream of library cataloging. By focusing on the treatment of several "hallmarks" of rare book records in codes published during the second half of the twentieth century, the development of rare book cataloging and its relationship to the traditions of bibliography and general library emerge.
\end{abstract}

\section{INTRODUCTION}

"Anything written on rare book cataloging just now is bound to be controversial." These words were written, surprisingly, in 1951, a time of stability and tradition compared to the modern library environment. The fact that an expert believed rare book cataloging to be controversial at midcentury underscores the forces that have shaped description and access for rare books through the present day.

This article will explore the development and character of modern rare book cataloging codes and practices, highlighting the constant tension between descriptive bibliography and library cataloging. The focus will be on the modern Anglo-American cataloging tradition, particularly as North American cataloging has developed distinctly from other traditions. Although cataloging codes have focused on descriptive cataloging, discussion of access is warranted in light of the different historical practices which, from the point of view of the uninitiated, often result in a multitude of unfamiliar access points and long, confusing bibliographic records. These differences become particularly significant when considering the relationship between rare book cataloging and special collections cataloging as well as the relationships between rare book cataloging practices and the application of those practices to other formats.

Finally, although theoretically descriptive cataloging codes are distinct from those practices dictated by bibliographic database requirements, practicing catalogers know that creation and editing of records are often based, not on intellectually correct goals of creating records, but on the exigencies of time, money, and the shared environment. Along with other environmental changes in libraries, rare book cataloging practices have accommodated the changing technological landscape, while catalogers have simultaneously attempted to benefit from the possibilities.

Although the history of the development of mainstream Anglo-American cataloging codes is a fascinating story, it will not be recounted here. Readers unfamiliar with the tradition are referred to surveys of the development of Anglo-American Cataloging Rules in its many manifestations. ${ }^{2}$ In 
addition, while previous articles have highlighted special aspects of rare book cataloging practices, such as the emergence of electronic indexes corresponding to special files, ${ }^{3}$ these valuable surveys have not always examined the intertwined aspects of description and access to rare materials. In addition, the ever-changing nature of library technology means that even the most complete survey is in need of constant revision.

\section{WHAT IS RARE BOOK CATALOGING?}

The term "rare book cataloging" is used for many different activities, ranging from full bibliographical description of an item, including quasi-facsimile transcription of the title-page, to the creation of bibliographic records with more than the usual number of notes. In the special collections world today, the term is usually applied to bibliographic records created using a set of descriptive rules specifically for rare books. It has been said, in another context, that "an unfamiliar convention often appears to be more difficult than it really is," and in this case, rare book cataloging codes, which are often unfamiliar to other librarians, have acquired the reputation of being inherently more difficult to understand and apply.

A helpful analysis of why separate cataloging codes for rare books are needed is provided by Laura Stalker and Jackie Dooley, who propose that there are two purposes for rare book cataloging rules:

1. To enable the precise identification of books on the basis of characteristics that do not relate solely to the works or texts they contain; and

2. To justify and explain access points which allow the user to identify books which possess these intellectual and physical characteristics. ${ }^{5}$

Although these aims do not differ in theory from the purposes of cataloging rules in general, it can be argued that the fundamental difference between mainstream cataloging codes and rare book codes is that "the object of description is essentially different", a printed book, pamphlet, or singlesheet publication produced either during the handpress period (before 1801 in the Western world) or using the techniques common during that period. This artifactual difference therefore accounts for special practices of description.

Received library history suggests that ancient and early medieval cataloging practices evolved primarily to inventory treasures, rather than to identify intellectual works. ${ }^{7}$ Exceptions, such as library finding aids and catalogs of remarkable sophistication, do exist, however, and catalogers (to use the term anachronistically) were able to make intriguing use of the technology at their disposal to provide description of and access to the works in their care. ${ }^{8}$

Nonetheless, the need for elaborate cataloging codes and practices only truly emerged with the explosion of printing and the growth of libraries. Originally inherently local in nature, these practices reflected the priorities of individual libraries and collections. As libraries grew, there were always some "treasure" books of historical significance or high monetary value that may have been described in a different way than the rest of the collection. However, the movement to create standardized cataloging, coupled with the growth of descriptive bibliography as a scholarly endeavor, were necessary for the emergence of true rare book cataloging rules.

\section{HALLMARKS OF RARE BOOK CATALOGING}

The province of rare book cataloging has traditionally been the descriptive areas of the 
bibliographic record, although these often go hand in hand with additional access points, which will be discussed below. Understandably, in the pre-computer library, the goal of providing adequate description was often in tension with the reality of limited card catalog space. While modern library systems make this less of a problem, the time, money, and effort necessary to describe materials must be balanced with the realities of contemporary library administration.

Before the emergence of cooperative cataloging standards, libraries treated rare books in their collections in any number of ways, and even today, codes and practices recognize the need for institutional flexibility. The entire bibliographic record is, in fact, potentially different in rare book cataloging from mainstream cataloging. Nonetheless, four representative elements of departure between rare book codes and general cataloging codes will be highlighted to focus the discussion and exemplify the philosophical differences underlying the codes.

\section{Transcription of Title Page Elements}

As title, author, and other information usually found on any book's title page is considered essential to identifying the piece, transcription of this information is not inherently different in purpose. However, the fullness or faithfulness of such transcription forms one of the more easily noticeable differences between rare book and "regular" cataloging records. Especially in early printing, typeface, exact wording of statements (such as the address for printers), line breaks, and other details distinguish among various editions, states, and printings of a title. Abbreviating publishers' names, for example, as is common in mainstream cataloging, can obscure valuable clues as to the identity and creation of the piece in hand. Other common practices, such as transcribing early letter forms in their modern equivalents ("v" to "u," for example) create more comprehensible records, but do not represent the text found in the book in hand.

Although it is often thought that rare book transcription is more time-consuming and difficult because it is more exact, Laura Stalker and Jackie Dooley suggest that faithful transcription provides "an accurate 'picture' of the object and is simpler to learn and practice than the transposition and normalization" mandated by mainstream descriptive codes. ${ }^{9}$ It is also worth noting that full transcription does not mean "quasi-facsimile transcription," a convention of descriptive bibliography which seeks to reproduce the appearance of the printed title page (as much as possible with modern typographical symbols) complete with capitalization, notation of borders and line endings, etc. The value of this practice is somewhat controversial, even among bibliographers. ${ }^{10}$ As we shall see, even though rare book cataloging codes have insisted on faithful transcription of title page elements, what constitutes such transcription has varied considerably.

\section{Format and Collation}

Handpress books were assembled using specific formulae related to the manner in which pages were printed. This formula is marked by signatures, "the letters (or, in some modern books, numerals) printed in the tail margin of the first leaf (at least) of each gathering or section of a book, as

a guide to the binder in assembling them correctly." 11 Recording both the signatures and the format of the book ("the size of a volume in terms of the number of times the original printed sheet was folded to form its constituent leaves") ${ }^{12}$ provides another method of distinguishing among manifestations of a title. Additionally, complicated formulae for recording such practices as removing and replacing leaves allow comparison of the copy in hand to both an "ideal copy" and to other copies known to exist. The system for recording collation is, in theory, rather simple, but becomes necessarily more complex as anomalies such as removal or addition of leaves, unsigned gatherings of leaves, and the like are accounted for in collational statements. 


\section{Notes}

To many people, one of the most obvious signs of a rare book record is the number and length of notes. Indeed, the means of production of handpress era books, in particular, ensure that more distinctive physical information is available to the cataloger and therefore will be recorded because of its value to users. At the same time, authoritative published descriptions in bibliographies for many geographic areas, time periods, or subjects make it common to record citations to these bibliographies (currently using MARC 510 field). Such notes, in combination with transcription and collation, can provide valuable evidence of the history of a particular book.

Copy-specific information is also more likely to be recorded although these conventions can be used in mainstream cataloging as well. Binding descriptions, provenance ("the pedigree of a book's previous ownership"), ${ }^{13}$ inscriptions, or annotations may convey important information in the context of a particular library or collection.

\section{Added Access Points}

Although descriptive cataloging codes have, until recently, confined themselves to the physical description of material, much of what is common in rare book cataloging practice also depends on added access points. Historically, rare book libraries often maintained special files tracing donors, types of bindings, or other characteristics that would not be searchable in traditional catalogs but which could be very useful to researchers working with the collection. The continued evolution of the MARC format allows for many of these access points to be indexed, even when the rare book records form part of a larger library catalog. Also, the development of specialized thesauri for providing controlled vocabulary access to terms outside the broader realm of sources such as Library of Congress subject headings allowed the application of these thesaurus terms as tracings within records. This combination of electronic access and standardized vocabulary gives "increased visibility-and perhaps respectability-to many of the features that were important reasons for the material to having been collected in the first place and which special collections librarians have always intuitively known were important bibliographic access points." 14

These are by no means the only differences between Anglo-American rare book cataloging rules and general cataloging rules developed during the twentieth century. The degree to which they appear in cataloging codes and manuals through the last half of the twentieth century makes them particularly symbolic of the approach of rare book cataloging.

\section{RARE BOOK CATALOGING AND BIBLIOGRAPHY}

It could be argued that there could have been no rare book cataloging on a national or international scale had there been no explosion in the field of descriptive bibliography during the late nineteenth and twentieth centuries. As scholars became increasingly interested in researching the physical attributes of books, it became desirable to record more of this information in catalog records. At the same time, bibliographers were developing sophisticated ways of communicating information about the physical structure and appearance of books that crept (and continue to creep) into rare book records. Two representative discussions will illustrate this point.

In his essential essay on the subject, G. Thomas Tanselle argues for cooperation and mutual understanding between bibliographers and catalogers, lamenting that the development of two separate specializations has resulted in more divergence between practices than in their compatibility. Writing in the late 1970s, Tanselle was aware even then of the role computers would play, both in the 
creation of union catalogs and in the spirit of cooperative cataloging that has since become a reality. He even goes so far as to argue for the emendation of the (then current) Anglo-American Cataloging Rules to include "the contributions which descriptive bibliography might make." 15

Nonetheless, Tanselle maintains the distinction between catalogs and bibliographies and, therefore, between the activities of cataloging and creating bibliographies. He enumerates the nowfamiliar distinction between a "catalogue," broadly defined as a record of the particular copies of books in a given collection, exhibition, etc., and a "bibliography" which concerns books which are related to each other but not with specific copies of those books. Bibliography, therefore, is concerned with the "ideal copy," which represents "a standard form of the book as published," and is, therefore, inherently an abstraction. This distinction has no relation to the amount of detail included in either a catalog or a bibliography although that difference has sometimes been advanced as well. ${ }^{16}$

Tanselle goes so far as to claim that both catalogs and bibliographies may result from certain types of bibliographic activity (e.g., "reference bibliography" wherein the concern is for works or "physical bibliography" wherein the concern is actual books), depending on the overarching purpose. ${ }^{17}$ In the areas of overlap, therefore, it is essential for cataloging and bibliography to be com-patible. ${ }^{18}$ Indeed, Tanselle enumerates two related approaches in attempts to reconcile at least the terminology used by bibliographers and catalogers: bibliographies "taking up the problems of description for those concerned with the physical book" and librarians writing "about the physical details appropriate for inclusion in the catalogue entries for certain classes of materials." An illuminating survey of the results of these two streams of writing follows. ${ }^{19}$

Rather than suggesting what information can be added to routine catalog records to make it useful for the purposes of physical bibliography, Tanselle instead argues that whichever physical details are presented in any catalog entry be intelligible, or at least not misleading, to the physical bibliographer. ${ }^{20}$ "Library cataloguers, for instance, need not employ the full pagination formulae of descriptive bibliography; but their formulae should then be unambiguously focused on the content of the books, so that no one will mistake them for attempts to record physical facts. ${ }^{, 21}$ This recognition that more is not necessarily better is essential to understand the requirements for a good rare book record.

Michael Winship also ties the distinction between bibliography and cataloging to one of purpose-in this case, to how well a catalog fulfills its objects. In terms of assisting the patron in finding or choosing particular books, Winship asserts that "a cataloging record will never reproduce the text in its entirety or satisfy the scholar's needs for the original, nor can it provide access to every possible point of scholarly interest." He would prefer catalogers focus on creating "short, accurate and clear records of a library's entire holdings" instead of "long, elaborated ones that conceal, and to some extent cause, a tremendous backlog." 22 Therefore, the relationship between bibliography and rare book cataloging should not focus on trying to create records that are as long, complicated, or detailed as entries in some bibliographies but rather on producing accurate and comprehensible records so that scholars, researchers, and even casual users can interpret them.

\section{DESCRIPTIVE CATALOGING CODES AND MANUALS}

Many general rules about description have remained more or less constant and will be familiar to anyone with knowledge of current cataloging codes and standards; this discussion will highlight rare book specific rules or interpretations rather than summarize entire contents of the codes. Before the 1980s, "various catalogs, handbooks, treatises and cataloging codes that could be used in whole or in part with profit in treating rare books," as well as "general rules in which little or no attention to rare 
books was given" (such as the American Library Association's rules of 1908, 1941, and 1949) were available, but these were not applicable to most libraries' entire collections, resulting in the proliferation of local practices. ${ }^{23}$ Nonetheless, it is worth examining both the specialized literature which fell short of full descriptive codes and the general codes, which paid little attention to rare books in order to understand the development of rare book cataloging practices.

In 1951 Paul Shaner Dunkin's How to Catalog a Rare Book appeared, specifically aimed at generalist librarians needing guidance in handling rare materials. This manual provides a very levelheaded and practical approach to cataloging, acknowledging the parallel needs to create records that are useful to experts and intelligible to other users. Dunkin also recognizes the realities of time and money constraining the work of the cataloger, even at mid-century. After discussing transcription, notation, and other practices in detail, illustrated with examples from rare books, he finishes his text with a summary of his approach so succinct and deliberate it merits quotation verbatim:

You can catalog almost any rare book adequately if you have an intelligent skepticism. The important thing is not so much what you do to the card as what you do to the book.

You will examine the book as a physical entity, and as you do so you will keep asking three questions: (1) Is everything what it seems or professes to be? (2) What features are significant? (3) Is the book complete?

Then, briefly and clearly, you will tell of every way in which that book may differ from all other editions and issues of that particular title and all other copies of that particular edition and issue. This means that you will give: (1) rather full title noting line endings, rules, and ornaments; (2) collation by gatherings in simple language; (3) collation by pages, the full contents, and sometimes other descriptive notes. ${ }^{24}$

In 1973, a new edition responded directly to the growing influence of descriptive bibliography upon rare book cataloging. ${ }^{25}$ In this edition, Dunkin responds to the transcription and collational formulae promulgated by writers such as Fredson Bowers in his Principles of Bibliographic Description. ${ }^{26}$ Through the middle years of the century, developments in bibliography exercised an increasing influence on rare book cataloging practices. Dunkin argues that bibliographers will have examined all copies of a given book, unlike catalogers, who do not have the luxury of such close examination. ${ }^{27}$ The idea that bibliographers and catalogers are doing fundamentally different things in describing books would continue to be echoed by other writers. Dunkin believes a simpler method of handling collational formulae than the system articulated by Bowers is "quite enough" 28 to convey the necessary information.

In discussing title page transcription, Dunkin suggests that catalogers take a "calculated risk," attempting to represent the content of the title page rather than taking the time and effort to construct elaborate systems to identify text. ${ }^{29}$ This practical recognition of the limits on the cataloger is also used to justify spot-checking of contents in order to identify copies although he acknowledges that "probably there is no such thing as a duplicate of an early book printed on the handpress.",30 Dunkin's work continued to influence rare book cataloging before and after the development of cooperative Anglo-American descriptive codes.

Anglo-American Cataloging Rules (AACRI) ${ }^{31}$

The publication of Anglo-American Cataloging Rules in 1967 did not, of course, represent 
the beginning of a codified approach to creating bibliographic records but rather built on earlier work. The preface acknowledges that $A A C R I$ (as it is now known) is based on general principles that have been followed as consistently as possible, rather than a code-based set of rules such as earlier publications. $^{32}$

$A A C R 1$ description serves two purposes: to make it possible to distinguish one work from another and also one edition of the same work from another. Annotation may be required to explain the nature and scope of the publication and its bibliographical relationships. The elements to be presented in the body of the entry are enumerated: title, author statement, edition statement, imprint, collation, series statement, and (if needed and if they can be stated succinctly) number of volumes, illustration statement, and the statement naming other persons, such as a translator. All other statements on the title page that contribute to the identification of the work should be presented "only if they are grammatically inseparable from other elements presented there, or if separation would require repetition of data in the body of the entry" (AACRI 130A-130B). All other information should be presented as notes (AACRl 132.A.1). Appendices list guidelines for capitalization, punctuation, and abbreviations.

Regarding the hallmarks of rare books cataloging discussed above, $A A C R l$ was a forerunner for later cataloging practice in a number of ways. The title proper should be recorded "exactly as to order, wording, spelling, accentuation, and other diacritical marks (if possible), but not necessarily as to punctuation and capitalization" (AACRl 133A). "Typographical peculiarities" such as the use of "v" for " $u$ " in nineteenth and twentieth century works are disregarded. Long titles are abridged "if this can be done without loss of essential information." Marks of omission are required. The use of line endings is allowed "only if all other methods of distinguishing two editions or issues of a rare book are inadequate," although there is no specific guidance about what might constitute such a situation. Author statements are transposed in most cases to their required position in the body of the text, according to rule 134B. The recording of numerals is spelled out in Appendix IV: as a rule, Roman numerals should be translated to Arabic, except in "the recording of a title or author statement, in the recording of pagination and references to pages, and in citing quoted matter."

One point of possible confusion in applying AACRl to rare books is the edition area. "Edition," so important in library cataloging, is not defined in the glossary and has often been understood in different ways, particularly when the concept is translated across languages. Representing the edition, along with states and printings, may be the essential element of the printing history of the book, and "an edition statement in a work is always included in its catalog entry, the impression or printing only in the case of items having particular bibliographical importance" (AACRl 135A). Interestingly, "no attempt is made to describe works in detail sufficient to identify them as issues" (that is, further discriminating than edition) except "in certain cases of rare books.",33

The "imprint" area shows place of publication, name of the publisher and the date (AACRI 138). A discussion outlines which parts of the publisher statement are essential and which are not, although neither is generally applicable to rare book cataloging (AACRl 140B-140C).

$A A C R l$ also offers a potentially confusing use of the word collation: "the cataloger's description of the physical work and consists of a statement of the extent of the work in pages, volumes, or volumes and pages, the important illustrative matter, and the size" (AACR1 142). The ambiguity between "work" and "book," as exemplified in this statement and others in the code, has not escaped comment. ${ }^{34}$ Examples of the pagination statement correspond to modern usage, for the most part; this does not address problems related to the sequences of unnumbered pages frequently found in rare books. ${ }^{35}$

In the note area, a note "to identify the work or edition and distinguish it from others" is 
considered the first of a list of "indispensable notes" enumerated in rule 144B1. Other type of notes that might be encountered in rare book cataloging, such as notes "to supplement the physical description in the collation" and "to provide bibliographical history of the work" are considered "important but not indispensable notes" (AACR1 144C2; 144C4).

Although technically limited to incunabula ("books produced in the infancy of printing," i.e., before 1500 in Western Europe), ${ }^{36} A A C R 1$ 's Chapter 8 "Incunabula" provides a model that might logically extend to early printed books in general given the lack of explicit guidance in handling later rare books. The first assumption is that incunabula often lack title pages or traditional "title page information," making it impossible to apply general rules of description. The second is that detailed descriptions of most incunabla have been published in standard reference works. These assumptions justify short-title entry, pointing to a fuller description elsewhere, rather than the detailed description common today. This desire to abbreviate was likely driven by the reality of space limits in card file catalogs.

Rules $180 \mathrm{~A}$ and $102 \mathrm{~A}$ guide recording of the title for incunabula. Interestingly, the title preferred is that found in a "competent authority," and only if that is not found should the title found in the work be used. The title printed in the piece itself, if it differs from the conventional form of the title, is to be recorded in a note (AACRl 184A). Also, imprint information is to be given in the form used as catalog entry, with the form used in the book itself following "if notably different." Dates, including the "exact date of publication, including day and month" if available, are recorded "according to modern style of chronology" (AACRl 182A; 182C). References to printed descriptions are required by rule 184B. They are to be given in a "brief but unmistakable form." Rule $184 \mathrm{C}$ allows for "elaboration of collation," including signatures "if the account is not given in a bibliographical source cited." "Peculiarities of the copy in hand" are suggested by rule 184E. Clearly, the catalog record is to be shorthand for the full bibliographical citation; transcription of information takes second place to standardized, intelligible access in catalog entry, and, in some ways, echoes manuscript cataloging practice more than book cataloging.

$A A C R 1$ formed the foundation of modern Anglo-American cataloging codes. Some apparent inconsistencies, such as "blind" references to rare books and a specific chapter applicable only to incunabula, must have been frustrating to those attempting to reconcile the cooperative rules with existing traditions of rare book cataloging.

The advent of the computer age in libraries saw the publication of another "non-manual" for cataloging rare books, The Cataloguing Requirements of the Book Division of a Rare Book Library. ${ }^{37}$ Josiah Bennett modestly begins his work by stating that if a "practical manual to cover all rare book operations could be prepared," he would not be the person to do it, referring "those who would like to see a fine example of rare book principles adapted to specific books and reduced to manual form" to the $A A C R l$ chapter on incunabula. ${ }^{38}$ Despite his deference, however, Bennett did compile a thorough overview of the issues involved in determining practice for rare book cataloging, focusing on university libraries' special collections.

He argues for an even briefer description in the catalog entry than Dunkin: "In almost any field in which reputable bibliographies exist . . . it should be obvious that citation of authorship and location of the reference, with a short identification of the state if called for, and description of the binding, will take care of the great majority of books." The extra time and effort put forth in cataloging will pay for itself in savings down the road, since recataloging or repeated investigation of the book will not be necessary. ${ }^{39}$ Bennett's practicality extends to his near revolutionary recommendation that "all wordage not essential to the identification of the work and all wordage duplicated or to be introduced more efficiently elsewhere" be removed from the transcription. This is, 
of course, to be coupled with references to standard bibliographies for identification. Bennett also argues that there are many instances "in which accurate title-page transcription in detail may be of great importance bibliographically-and in which the library cataloguing form of transcription is of no use whatsoever." 40 His attitude extends to the imprint, where he calls for consulting speakers of unfamiliar languages in order to avoid transcribing unnecessary information; transcription, if preferred, should be "with free use of the ellipsis."

While acknowledging that elaborate collation is rarely necessary, he does state "the reduction of the page collation to the mere recording of the last page number found has absolutely no place in rare book or special collections cataloging." He goes so far as to emphasize the importance: "ALL COLLATIONS OF EVERY TYPE . . . MUST REPRESENT WHAT IS ACTUALLY PRESENT, NOT THE IDEAL COPY." ${ }^{, 42}$ Despite his disclaimer, the book emerges as a true manual of rare book cataloging, focusing on the brevity of records so important in a card catalog age. Bennett's work does seem to assume, however, that establishing the bibliographic identity of a book is a relatively simple matter, and that the cataloger can easily record such information in an intelligible way.

\section{Anglo-American Cataloguing Rules, Second Edition (AACR2) ${ }^{43}$}

A major development in rare book cataloging came with the inclusion in the second edition of $A A C R$ (published in 1978) of specific rules designed to allow description of early printed monographs, not just incunabula. Rule 2.12 specifies the scope of their application: "books, pamphlets, and broadsides published before 1821 in countries following European conventions in bookmaking." They are designed to supplement rules in Chapters 1 and 2.1-2.11 (the corresponding sections of the "Books, Pamphlets and Printed Sheets" chapter) and are to be used "only when the conditions they state apply to the early book, etc., or when, as in 2.16 , they contain instructions different from previous rules." The inclusion of such rules in a mainstream catalog code is so important it merits close scrutiny.

Rule 2.13 provides for a hierarchy of choices to be consulted as the chief source of information when the book has no title page. This is a departure from the general rule (AACR2 2.0B1) that states only to use "the part of the item supplying the most complete information." Instructions as to the abridgement of long titles proper found in $2.14 \mathrm{~B}$ call for the omission of alternative titles, which contradicts later rare book rules. Rule 2.14E covers transcription of early letter forms, calling for a degree of modernization one might expect in a mainstream cataloging code. For example, when the text does not distinguish between " $v$ " and " $u$," the rule calls for transcription as "u," suggesting this is the most common modern usage. Edition statements are to be transcribed "as . . found in the item," with the option to use standard abbreviations and Arabic numerals "if an exact transcription is not desired."

Rules governing the publication, etc., area would be familiar to rare book catalogers today. Examples include treating the bookseller, bookseller-printer, or printer as a publisher if appropriate (AACR2 2.16A), transcribing the place of publication as found in the item (AACR2 2.16B), adding the full address or sign of the publisher, printer, etc., "if it aids in identifying or dating the item" (AACR2 2.16A). Rule $2.16 \mathrm{H}$ calls for recording the date of publication or printing "including the day and month," although Roman numerals are to be changed to Arabic in recording the year. An option allows for "formalization" of a very long date statement. The format is recorded in abbreviated form after its dimensions (AACR2 2.17C).

The identification purpose of rare book cataloging is clearly acknowledged in the section on notes. In addition to the requirements that certain types of notes be made in records for incunabula, 
rule $2.18 \mathrm{~A}$ instructs: "If the formalized description of the areas preceding the note area does not clearly identify the edition or issue being catalogued, make all notes necessary for unambiguous identification." Catalogers experienced with rare books might wish it were that easy to provide unambiguous identification. Bibliographic references and signatures/foliation are prominently mentioned (AACR2 2.18C-2.18D). Rule 2.18F, corresponding to $2.7 \mathrm{~B} 20$ for non-rare books, shows a greatly expanded set of examples for copy-specific notes, including imperfections, binding, inscriptions, etc.

The inclusion of special rules, however brief, for early printed materials was an important first step in the development of special rare book rules within the Anglo-American cataloging tradition. The special chapters in $A A C R 2$ designed for other formats attempted to provide a unified approach to describing the growing universe of library materials, and rare books (defined solely by age, in this case) took their appropriate place. Despite the philosophical coherence signaled by this change, these rules would shortly prove to be inadequate.

\section{ISBD(A): International Standard Bibliographic Description for Older Monographic Publications (Antiquarian) $^{44}$}

Parallel to the development of Anglo-American cataloging codes was the development of the standards issued under the auspices of the International Federation of Library Associations, International Standard Bibliographic Description (Monographic Publications) or ISBD $(M)$. In response to dissatisfaction among those working with rare books with the revised draft $I S B D(M)$, an explicit statement was added in the published version: " $I S B D(M)$ is primarily concerned with current publication. It therefore makes no provisions for the special problems of older books." records for older materials tended to exist in separate catalogs, and, in 1973, "there was little demand for machine-processing of records for any but current items."

The growth of large cooperative databases for antiquarian materials, however, led to the realization that electronic manipulation of bibliographic data could be just as useful to those working on handpress era books as to current cataloging. A draft version of $I S B D(A)$, (with the "A" standing for Ancien, Antique, Antiquarian, Alt, etc., conveniently encompassing most European languages) emerged from an IFLA working party in 1975, but at the same time, the entire framework of the ISBD was being revised. The Rare Books and Cataloguing Sections of IFLA therefore established a Working Group to examine the applicability of $\operatorname{ISBD}(M)$ to description of older books. The Working Group assumed that:

descriptions of older books are usually formulated for a somewhat different purpose from that guiding the professional skills of those recording current information ... older books are considered as artifacts to be described in such a way as they can be clearly distinguished for the purpose of comparison with other copies and other editions of the same work. The aim of the rare book librarian here is not only description of an antique, but, more important, the clarification of the transmission of the text and the "points" which distinguish editions. ${ }^{46}$

Without resorting to title-page transcription, ("that is for the literary bibliographers,") "such descriptions should pay close attention to detailed accurate transcription of the two areas of the title and the imprint and give an exact statement of the extent of the work as published." Therefore, it is not a book's age which makes $I S B D(M)$ unsatisfactory, but the distinct characteristics of the handprinted book, which dominated in Western Europe until around 1820. Later publications produced 
by hand "or by methods continuing the tradition of the hand-produced book" are also within the scope of the rules $(I S B D(A)$ 0.1.1). Title, imprint and collation are therefore the three areas in which $\operatorname{ISBD}(A)$ departs from $\operatorname{ISBD}(M)$ "in detail, but not in principle." This scope signals the growing importance of modern fine printing and other types of special collections beyond purely antiquarian books.

International dialogue and comment followed the drafting and revision of the rules, and they were approved (with one exception) by the Standing Committees of the IFLA Sections on Rare and Precious Books and Documents and on Cataloguing in January 1980. Clearly defining the roles of cataloging vs. bibliography, the introduction states "The $\operatorname{ISBD}(\mathrm{A})$ is intended to provide for the description of older books in general catalogues, bibliographies and databases containing records of approximately equal detail for books, and other library material, of all periods . . . It is not, therefore, a set of rules for the full bibliographical description of older books . . ." Options are given to allow flexibility based on institutional needs. “. . . [F]or those items which appear to defy any rules, I can offer only the advice to act by the spirit of $\operatorname{ISBD}(\mathrm{A})$ and employ common sense.",47

One of the major contributions to cooperative cataloging from the development of the ISBD concept is that punctuation which has come to be known by its name. For rare books, "ISBD punctuation" becomes even more significant. Rule 0.4.1 introduces what is commonly, but mistakenly, called "double punctuation." "Bibliographic agencies . . . may wish to record a full description incorporating the full punctuation, i.e., the exact punctuation as found on the item and as given in the sources of information. When full punctuation is recorded ... the prescribed punctuation is also given, even though this may result in double punctuation." Rules governing the options in this case have led to confusion among catalogers ever since; punctuated information within the framework of ISBD signals the type of information, while transcription dictates punctuation based on the usage of the piece in hand.

The title is to be recorded "exactly as to wording but not necessarily as to capitalization or punctuation ... Exceptionally, a very lengthy title proper may be abridged in the middle or at the end" with marks of omission $(I S B D(A)$ 1.1.2). "Initials indicating membership of societies, academic degrees, etc., and statements of positions held and qualifications following an author's name are generally omitted from the statement of responsibility," unless necessary for grammar, identification, or for providing context $(\operatorname{ISBD}(A)$ 1.5.3.1). Explanations of the relationship between the statement of responsibility and the title "may be used within square brackets to link the title and statement of responsibility" $(\operatorname{ISBD}(A)$ 1.5.1.1). "Statements on the title-page or title-page substitute which are not connected with responsibility for the intellectual or artistic content of the work(s) contained in the publication and do not constitute other title information . . . are omitted." These would include mottoes, dedications, statement of patronage, etc. $(I S B D(A)$ 1.5.10).

Transcription of early letter forms is covered by rule 0.8 . Where practice is not consistent, "i" and "j" are transcribed (in most cases) as "i," "u" and "v" as "u." An initial "u" or "v," is to be transcribed as a "v," and specific rules apply to other instances, as well. This departs from guidelines given in $A A C R 2$. Another early printing convention covered is the virgule (/) used as a comma. It is to be transcribed as a comma, and "in case of doubt the usage of the text of the work is followed."

"The names of publishers, etc., are given as they appear in the publication in the full orthographic forms and the grammatical case (with necessary preceding works and phrases) in which they are given in the preferred principal source of information." Provision is made to add addresses "when they aid in identifying or dating the publication" $(\operatorname{ISBD}(A)$ 4.2.2.1). Detailed rules govern transcription of names for various functions of printer, publisher, bookseller, etc. $(I S B D(A)$ 4.2.24- 
4.2.26). "Dates are given as found in the publication, including the day and month. Years of the Christian era and dates taken from a chronogram are, however, given in Arabic numerals. Phrases such as "printed in the year ..." and "anno ..." are omitted. Very long statements may be formalized. Dates not of the Christian era are transcribed, with the equivalent added in square brackets $(\operatorname{ISBD}(A)$ 4.4.2).

Signatures are first mentioned in rule 5.1.2.6.C, which allows for a statement of extent by signatures as one option in a wholly unpaginated or unfoliated work. In other cases, "the register of signatures may be given in a note." Rule 5.3.2 states: "the bibliographic format of the item is given in the terms of a numeral (including a fraction) followed by a raised o or similar abbreviation," followed by the item's height.

In discussing the inclusion of notes in the bibliographic record, $\operatorname{ISBD}(A)$ acknowledges that the enumeration of notes cannot be exhaustive but should or may include such types as the bibliographic reference note $(I S B D(A) 7.1 .1 .1)$. Notes on the edition area and the bibliographic history of the publication $(\operatorname{ISBD}(A) 7.2)$ allow for description of earlier manifestations of the text as necessary. Notes can also provide clarification or expansion of publication, distribution, etc., information (ISBD $(A)$ 7.3).

An attempt to include an analog to the International Standard Book Number concept in rare books allows for the optional inclusion of the fingerprint, which "consists of a number of characters drawn from a number of uniform places in the text of the publication, followed by a number indicating the source of one or more of the characters, and/or a letter indicating the direction of the chain-lines, and/or the date as it appears in the imprint." The use of a fingerprint "has been considered as a substitute for the standard number for older publications," but no definitive formula had been determined $(\operatorname{ISBD}(A)$ 8.1.1-8.1.3). The limitations of the fingerprint as a standard led to its rarity in North American bibliographic records. $\operatorname{ISBD}(A)$ included no provisions for creating headings or uniform titles $(I S B D(A) 0.1 .3)$, as it was designed as a purely descriptive code.

\section{Bibliographic Description of Rare Books $(B D R B)^{48}$}

As the second edition of $A A C R 2$ was being prepared, rare book catalogers and librarians realized the brief section on rare printed materials at the end of the second chapter "might benefit from some expansion and elaboration to address in a more complete way the often troublesome questions of rare book description." Since there was not enough time to incorporate most of the provisions of $I S B D(A)$, published in first draft in 1977, into $A A C R 2$, the progress of $I S B D(A)$ through drafts was watched with interest. It became obvious that what was needed was "a single cataloging standard, based on $A A C R 2$ but approaching the cataloging of rare materials with the thoroughness of $\operatorname{ISBD}(A) . " 49$

At the same time, the importance of electronic cataloging in the context of rare books was becoming greater. The Eighteenth-Century Short Title Catalogue (ESTC) project was being planned, along with Independent Research Libraries Association's Ad Hoc Committee on Standards for Rare Book Cataloging in Machine-Readable Form. ${ }^{50}$ In June 1979, the Library of Congress began to prepare rules for descriptive cataloging of rare books under $A A C R 2$, combining Chapters 1 and 2 plus $I S B D(A)$ rules. Bibliographic Description of Rare Books was published in 1981 as "the Library of Congress' interpretation of $A A C R 2$ Chapter 2 for its own cataloging of older printed materials." Contributions and comments were made by many other groups and libraries.

One of the primary assumptions of the rules that emerged is that "elements of data from a publication are generally transcribed as they appear, frequently without transposition of the other forms of intervention practiced by catalogers of ordinary books under AACR2." This necessitates using other 
forms of entry (such as uniform title) to allow access by strings that would be expected to retrieve the records, had more familiar rules been used. Also, the rules apply to "any printed books, pamphlets, broadsides, and single sheets requiring special description," based on the following criteria: date of printing, place of origin (particularly where books are printed by hand), and administrative policy of the institution. In this way, the application of the rules may vary from library to library, within libraries by particular collections, or even book by book. The Library of Congress applied $B D R B$ for books printed before 1801, with $A A C R 2$ being used for later books (BDRB 0A). Libraries could, of course, apply $B D R B$ much more broadly.

Rule $0 \mathrm{E}$ allows recording all punctuation, giving the prescribed punctuation as well, although the Library of Congress will omit punctuation in source if application of ISBD punctuation would result in "double or duplicate punctuation." Rules for the transcription of early letter forms were similar to those in $\operatorname{ISBD}(A)$, yet allow for even more variation based on capitalization $(B D R B 0 \mathrm{H})$. Rule $0 \mathrm{~J} 2$ calls for expansion of marks of contraction, with supplied letters (or words) enclosed in brackets. Apparently conflicting with the goal of exact transcription, however, initials, initialisms, and acronyms are to be recorded without internal spaces, "regardless of how they are presented in the source of information" (BDRB 0K).

A potential source of confusion through the code, particularly for those not working with it on a regular basis, is the seemingly arbitrary decision of when omissions are to be shown with marks of omission and when such marks are not to be used. The title and statement of responsibility area allows omission (without mark of omission) of information that is neither title nor statement of responsibility information (BDRB 1A2). Familiar rules cover transcribing, supplying, etc., the title. The title proper is, in general, not to be abridged, but when abridged "in exceptional cases" marks of omission must be used (BDRB 1B8). Acknowledging the differences in broadsides, rule $1 \mathrm{~F}$ provides rules for recording titles of single sheet publications, usually beginning with first line of printing.

Rule $1 \mathrm{G}$ calls for transcription of statements of responsibility "in the form in which they appear" including titles, honorifics, etc., although the statement can be transposed if it appears above title, for example. Initials, degrees, etc., are to be omitted in most cases according to rule $1 \mathrm{G} 8$, with the same exceptions applying as in $\operatorname{ISBD}(A)$.

An important difference between $A A C R 2$ and $B D R B$ is that the edition statement is to be recorded in the form in which it appears (BDRB 2B1). Exact wording is to be used unless the statement is taken from a source other than the title page, in which case it can be abbreviated and standardized.

"Because these rules are for both early printed books, for which the modern functions of printer, publisher, and distributor are often still undifferentiated, and for later books, in which information about the printer may be of particular importance or interest, the name and location of the printer are here given equal status to those of the publisher and distributor" (BDRB 4). This results in longer, more detailed transcriptions of imprint than $A A C R 2$. The place of publication is to be transcribed as it appears, and it can include prepositions, larger jurisdiction names, exact transcription of abbreviations, etc. (BDRB 4B1-4B4). If necessary to distinguish among places, further information such as state or province can be supplied, as in $A A C R 223.2 \mathrm{~A}$, although when supplying such a name, $B D R B$ calls for using "name or form appropriate to the date of publication." This avoids anachronistic phrases placing a publication in a nation not yet in existence. If publication information is given, the printer can be recorded in a note (BDRB 4E1). Rule 4D covers date; date of publication is recorded "as found in the publication" although Roman numerals are to be changed, as usual, to Arabic. Some phrases, such as "printed in the year" are to be omitted. Optionally, the information can be transcribed exactly "if it is considered important to retain in the catalog record the exact wording of imprint information," in 
which case, Roman numerals can be used with Arabic added in square brackets afterwards. Special explanation (as in $\operatorname{ISBD}(A)$ ) is given for historical calendars, expanded beyond the scope of $A A C R 2$ to account for their incompatibility with the modern Western calendar during various time periods.

In the description area of the record, (BDRB 5B), blank leaves are generally counted. Advertisements are included "if they clearly belong to the publication." Unnumbered pages or leaves are counted, in appropriate terms. Also, if they interrupt a numbered sequence, the record should make this explicit. When a whole volume is unnumbered, pages are to be counted, contrary to $A A C R 2$ rule $2.5 \mathrm{~B} 7$. Several sequences are "preferably" to be recorded, although the option of using the phrase "various pagings" still exists.

After the publication's size, the bibliographical format is to be added, in abbreviated form, and if it can be determined. This is required for publications before 1801 and optional for later publications (BDRB 5D1).

$B D R B$ provides for similar notes as in $\operatorname{ISBD}(A)$ : Rule 7C9 instructs "make a note giving details of the signatures of a volume, if desired,"52 according to the formula published in Philip Gaskell's New Introduction to Bibliography. ${ }^{53}$ Therefore, one of the most visible clues in a bibliographic record that rare book rules have been used is actually optional. The reference to Gaskell's important treatise also underlines the influence of bibliography on rare book cataloging.

Rule 7C14 calls for references to published descriptions to be recorded in a standard and abbreviated form; the Standards Committee of the Rare Books and Manuscripts Section of ALA, in cooperation with the Library of Congress, was noted as preparing a list which should be used in any note. A short list of sources which should be recorded includes standard American and British bibliographies. $^{54}$ This type of short list of standard bibliographies would eventually develop into a reference for not only the bibliographies, but also standardized forms for citations to them. ${ }^{55}$

"Copy specific information," often forming the bulk of a bibliographic record, is discussed in rule $7 \mathrm{C} 18$. $B D R B$ states that the Library of Congress will not use fingerprint technique as an analog to standard numbers (BDRB 8).

The code concludes with ten examples of catalog records constructed according to the rules, plus a very brief glossary. Some definitions are taken from another article by Tanselle, ${ }^{56}$ highlighting the overlap between rare book cataloging and bibliography. Although no index was included in $B D R B$, the subsequent publication of an index by David M. Rich suggests it was very useful to be able to find information in this manner. ${ }^{57}$

Another result of $B D R B$ was to serve as the impetus for other specialized codes to be used with rare materials, ${ }^{58}$ including graphic materials, ${ }^{59}$ archives and manuscripts, ${ }^{60}$ and rare serials. ${ }^{61}$ As we shall see, these related cataloging codes followed paths of revision and updating much the same way as $B D R B$ itself. Since $A A C R$ included rules for all formats, this development paralleled in many ways the evolution of format-based codes, acknowledging the insufficiency of general codes to provide enough guidance to catalogers in handling specialized, non-book formats.

\section{Anglo-American Cataloguing Rules, 2nd ed., 1988 Revision (AACR2R) ${ }^{62}$}

Along with other changes in the 1988 revision of AACR2, rules 2.12-2.18 were revised. The scope rule $(A A C R 2 R$ 2.12) includes a specific injunction to "consult specialized reference materials for more detailed treatment of early printed books, etc.," acknowledging that the circumstances governing printing, binding, distribution, and other facets of the book trade cannot adequately be understood without further study.

The transcription of early letter forms rule (AACR2R 2.14E1) was simplified. "U" is transcribed as "u," but as " $\mathrm{v}$ " if the first letter of the word. "V" is also transcribed " $u$ " in this case, 
unless it is the first letter. This may still be confusing to those not used to working with early letter forms and orthography. The publication, etc., area was overhauled considerably, and simplified. The overarching principle in the 1988 revision is to "give the rest of the details relating to the publisher, etc., as they are given in the item" (AACR2R 2.16D). With the 1988 revision of $A A C R 2$, the importance of special rules for rare book cataloging was confirmed, along with movement in the direction of faithful transcription, despite the exigencies of mainstream cataloging rules.

$\operatorname{ISBD}(A)$ was also revised soon afterwards. ${ }^{63}$ The general theme of this standard is the same as its earlier edition, for example, in seeking exact transcription but attempts to conform more to the other $I S B D$ standards. It, along with other revised ISBDs, also accounts for non-Roman scripts and languages. ${ }^{64}$

\section{Descriptive Cataloging of Rare Books $(\text { DCRB })^{65}$}

By the early 1990s, the influence of electronic cataloging was being felt in rare book cataloging codes in an explicit way, indicating the increasing prevalence and sophistication of bibliographic databases and integrated library systems. Subsequent codes would acknowledge this reality, as well as moving towards integrating concepts of description and access in ways unknown in previous codes.

Nearly ten year's experience with $B D R B$ by rare book catalogers along with the revision of $I S B D(A)$ prompted review of the code, ${ }^{66}$ marked by cooperation between the Library of Congress and the Bibliographic Standards Committee of ACRL/RBMS. A survey distributed in 1989 by the BSC generated a great number of responses, including feelings of confusion about some provisions of $B D R B$, particularly early letter forms, inconsistencies in transcription rules, and the need for general updating and indexing. The code which resulted from these revisions, although called a second edition, was named "Descriptive Cataloging of Rare Books" instead of "Bibliographic Description of Rare Books" as an effort to address the ongoing confusion between bibliography and rare book cataloging. ${ }^{67}$

The committee decided to proceed with two basic assumptions: "a rare book cataloging code should be driven by the characteristics of early printed books" and "harmony among related and analogous codes is desirable." Following this thinking, "a separate descriptive code for rare books, and each particular rule within it, can be justified only if it results in catalog records that are used in ways that general catalog records for books are not." Therefore, while not fundamentally contradicting the prevalent cataloging code $(A A C R 2)$, rare book codes differed in numerous ways. "It can be maintained that the fundamental difference between $A A C R 2$ and $B D R B$ is that the object of description is essentially different." Usually, the difference is based on criteria (bibliographical or artifactual value) related to age (pre-1801). ${ }^{68}$ Of course, for libraries with small collections of rare materials, it would likely be too difficult to apply multiple codes; most of these libraries would use $A A C R 2$ 's provisions, rather than a separate rare book code. ${ }^{69}$

Another problem with $B D R B$ acknowledged by the committee was the proliferation of options designed to allow flexibility based on local needs; these actually had the result of making identification of items (one of the primary goals of a catalog) difficult, since libraries could have cataloged the same item in many different ways. This is especially confusing in bibliographic databases, resulting in multiple records. Internal consistency was another goal of the revision. Some inconsistencies remain between $D C R B$ and $\operatorname{ISBD}(A)$, such as transcriptions of early letter forms, prescribed source of information for edition statement, and the placement of bibliographic format in description area. ${ }^{70}$ Nonetheless, cataloging at the Library of Congress (and, by extension, those libraries following LC practice) must follow the rules $(A A C R 2)$ rather than the standard $(I S B D(A))$, 
and $D C R B$ allows them to do that. ${ }^{71}$

Perhaps the most important change in the revision was the evolution toward creating a cooperative rare book cataloging manual, instead of a descriptive code, including advice on access points, serials, MARC coding, etc. ${ }^{72}$ The resulting publication has several appendices: title access points, early letter forms, rare serials, minimal-level records, DCRB code for records (used in the 040 field to indicate rules used in constructing the record), concordance between $D C R B$ and $A A C R 2$ rules, and a glossary, much expanded from $B D R B$.

Appendix A: Title Access Points, is the first indication that $D C R B$ is going beyond the scope of descriptive rules. The creation of additional title access is necessary because $D C R B$ calls for transcription without "transposition or the other forms of interventions practiced by catalogers of ordinary books under AACR2." Characteristics of the early books themselves, such as a lack of title page or the use of contractions, also make it essential to provide additional access in order to identify and locate books. The subsequent rules, arranged to correspond with parts of the description, provide a suggestive rather than exhaustive list of entries with the goal of providing "thorough access by title.,"73

Another departure from past codes was the inclusion of Appendix C: Rare Serials, expanding on guidelines published in 1984 and incorporating changes from the CONSER Operations Committee and CONSER Operations Coordinator. ${ }^{74}$ The scope of application is all serials published before 1801 and later ones for which a more detailed level of description is desired (DCRB Appendix C, 1.1). In sum, the rules call for liberal application of notes, more faithful transcription of serial designations, and addition of bibliographic format where appropriate. The United States national serials database's need for consistent records (in choice of title) led to the admonition to not apply the DCRB provision in rule $1 \mathrm{~B} 1$ that allows including within the title proper statements that appear before the chief title on the title page. Provisions for cataloging individual issues of serials are also provided, largely calling for treatment as monographs, along with guidance for linking such records to the master serial record (DCRB 3.1-3.5).

The text of $D C R B$ itself begins with a list of works cited that forms a short list of "rare book cataloging tools." 75 The need for this type of primer for rare book cataloging, especially referring novices to sources of more detailed information on book production, binding, etc., continues even today. ${ }^{76}$ Appendix E makes a clear distinction between rare book cataloging and "special collections cataloging," defined as "fuller use of notes, access points, and other elements that are not specifically called for in AACR2 or its predecessors, but that follow the spirit of DCRB without following its rules exactly."77 Confusion often clouds this distinction, particularly for those unfamiliar with bibliographic records for special collections material.

While in some ways, $D C R B$ was a more complete manual than its predecessor, it could not include all things necessary to catalog rare books. The examples of full bibliographic records which had appeared in $B D R B$ were removed, but the subsequent publication of a separate volume of examples proved much more ambitious. ${ }^{78}$ Work on this volume began almost immediately after DCRB's publication. The examples were aimed at illustrating $D C R B$, with particular emphasis on unusually complex rules. They also illustrate options, showing how different applications would appear in real bibliographic records.

The justification for such a volume was that "variations in printing practices, lack of standardized title pages in early works, range of languages, and the artifactual aspects of rare books can all pose problems for the cataloger. Through use of examples, these potentially difficult areas can be clarified." The examples were never meant to be used as substitutes for the rules which they illustrate. The examples are MARC coded, using "generic USMARC" instead of local applications used by OCLC or RLIN. Subject headings are omitted from the records since subject access is essentially the 
same for rare books and other books, but some additional access points are included to illustrate particular rare book practices. ${ }^{79}$

Another spin-off of $D C R B$ was the eventual emergence from "Appendix D: Minimal-Level Records" to the "Core Standard for Rare Books," which was approved in January 1999. This standard is the rare book component of a core record project devised under the direction of the Program for Cooperative Cataloging (PCC), administered by the Library of Congress with input from libraries throughout the world. Simply put, most notes allowed for in DCRB have been omitted, and, where options exist, areas are abbreviated. The $D C R B$ standard differs from the PCC "Core Bibliographic Record for Books" in a few ways: there is no requirement for a nationally standard classification since many libraries use local call numbers for rare books; notes are to be recorded "as to method" more like $D C R B$ records than $A A C R 2$, although, of course, they can be abbreviated; citations are encouraged where appropriate; and genre terms are to be used if local policy requires. ${ }^{80}$ The use of this standard will fulfill one of the major needs seen by Melissa Flannery in 1986: minimal standards of completeness so that "records contributed to databases on a national and international level will have enough consistency to provide accurate information for the online retrieval of various lists and indices which technology has made possible." $" 81$

As of this writing, the ARCL/RBMS Bibliographic Standards Committee is engaged in a revision $D C B R$ with the long-term goal to produce a series of volumes more appropriately titled DCRM: Descriptive Cataloging of Rare Materials, with separate portions for books; music; serials; cartographic materials; ancient, medieval, and early modern manuscripts; etc. Work on these modules is underway, with appropriate bodies being consulted, or, in some cases, creating rules in consultation with BSC. ${ }^{82}$

This emerging North American standard for all rare materials will solve one of the perceived shortcomings of descriptive codes up to this point: their focus on the book format. Since catalogers often work in specific formats independent of age or rarity of materials, expanding provisions to capture important artifactual or bibliographic information about these formats will provide a useful tool for catalogers, particularly those used to working with a specific format chapter of $A A C R 2$. The ongoing process of revision continues the drive for consistency and for removing confusion that undergirded revision of $B D R B$ into $D C R B$.

\section{ACCESS POINTS}

Descriptive records do not exist in a vacuum. Most libraries also classify and provide subject access to their collections; but, for the most part, this practice will not differ substantially for rare books from the practice used for mainstream materials. (Obviously preservation needs may prevent marking of books, and other local conventions may apply, but the principle nonetheless holds true.) These basic types of access points, however, are often not seen as sufficient to point researchers toward specific types of material.

Josiah Bennett referred to a common practice in administering rare book libraries, "set[ting] up specialized files in non-subject areas for more efficient scholarly and bibliographical use of rare books. Tracing to such files often has the great value of reducing the detail on the catalogue card, making a specific aspect of the book traceable in its own right." Suggestions for special files include imprint files, association files, printers' files, and binders' files. ${ }^{83}$

One of the most visible ways in which the English-speaking North American rare book cataloging community has strived to make possible access to specialized types of information in bibliographic records is the creation and ongoing maintenance of several thesauri. Here, as in the 
construction of descriptive rules, the Bibliographic Standards Committee of ACRL/ALA has been the driving force. Beginning in the 1980s and continuing today, assembly and revision of several thesauri for rare books cataloging have provided standardized vocabularies, ${ }^{84}$ supplementing the "mainstream" vocabularies produced under the auspices of the Library of Congress. The first thesaurus to appear centered on terms to describe bindings, highlighting the importance of this type of information in traditional rare book records. ${ }^{85}$ The introduction of field 755 ("Physical Characteristics Access") into MARC in 1984 necessitated a controlled vocabulary if such characteristics were to be described in a uniform way. Binding Terms "presents terms for the description of bookbindings and includes descriptors relating to techniques for binding construction, and to the style, materials, and decoration of bindings." 86

A similar need to standardize access points based on emerging technology drove the publication of Genre Terms in $1983:^{87}$

Many rare book libraries maintain files of certain categories, or genres, of works found in their collections. These files include both intellectual or literary genres which characterize works (e.g., Courtesy books) and physical genres which characterize physical manifestations of works (e.g., Miniature books). The files are especially useful when an item is sought not through conventional author, title, or subject approaches, but rather through a term descriptive of the category into which it falls. Indeed, many items in rare book libraries are chiefly of interest to researchers as representatives of intellectual or physical genres. ${ }^{88}$

These terms were aimed at exceeding the depth and specificity allowed by using Library of Congress subject headings as form/genre terms. The development and use of MARC field 655 allowed for automated retrieval of this type of information, rather than relying on manual files. Its use was acknowledged to be voluntary and selective. ${ }^{89}$ Arguably the most used of the thesauri, a new edition of Genre Terms was published in $1991 .^{90}$ Other thesauri produced include vocabularies for printing and publishing evidence, ${ }^{91}$ provenance evidence, ${ }^{92}$ paper terms, ${ }^{93}$ and type evidence. ${ }^{94}$ The ongoing process of revision of these thesauri includes submission and public comment under the auspices of the Bibliographic Standards Committee. ${ }^{95}$

In addition to the rare book thesauri, catalogers have available to them other vocabularies designed by specific communities, usually based on format of materials. For example, the Art \& Architecture Thesaurus might be used to describe works of art or material culture. ${ }^{96}$ While use of these vocabularies allows for a greater breadth and depth of access for special collections, the lack of reconciliation between vocabularies means that, in reality, the collocation features of standardized terms may be lost. ${ }^{97}$

Added name entries assume a special prominence in rare book records based on the tradition of tracing many more names associated with items than in mainstream cataloging. Scholars might use such tracings to reconstruct the work of a given printer or bookseller or to study the development of illustrative techniques by searching for the work of a particular engraver or lithographer. In addition, copy-specific tracings for former owners, donors, and the like are often traced. $A A C R 2 R$ allows functions to be added to tracings: "In specialist or archival cataloguing, when desirable for identification or file arrangement, add designations from standard lists appropriate to the material being catalogued" (AACR2R 21.0D1). This justifies the inclusion of names (either personal or corporate) in a bibliographic record in an intelligible way. For North American rare book catalogers, the standard English-language list is the relator terms maintained by the BSC. ${ }^{98}$ The MARC codes which correspond to these terms are incorporated into the "MARC Code List for Relators, Sources, 
Description Conventions" maintained by the Library of Congress. ${ }^{99}$

A final type of special access has been alluded to previously: title access. As has been acknowledged since $B D R B$, the exact transcription called for by rare books rules requires added entries in order to facilitate retrieval by title. Uniform titles are also likely to play a large role, especially in early printed books. Format integration has, not surprisingly, broadened the possibilities of providing access to titles in useful ways. Although acknowledging that this problem is not unique to rare books, Bennett, for example, opined: "While our learned friend may turn immediately to the cards for Travels into several remote Nations of the World, we must also serve those who will look first under Gulliver's Travels."

\section{BIBLIOGRAPHIC DATABASES AND INTEGRATED LIBRARY SYSTEMS}

Increasingly, the structure and functioning of library integrated systems are responsible for how individual bibliographic records are retrieved, displayed, and organized. The de facto national (or international) databases of OCLC and RLIN have rules and procedures that govern when new records can be added as well as how local information can be presented. In OCLC, in particular, the traditional library cataloging function of describing the copy in hand becomes less clear since the master record ought to retain little of the copy specific information so valuable in rare book records. Particularly for catalogers working in larger institutional contexts, the choice of when and how to create a bibliographic record may be governed by these databases rather than by specialist codes.

At the same time, local integrated library systems play a huge role in the creation of rare book records as well. Obviously, the increasing sophistication of such systems has provided many outstanding ways to provide access to collections. Theoretically an unlimited number of indexes could be provided without the manual work required in card catalog days, allowing for tracing of donors, printers, engravers, and others types of names. Additionally, keyword searching promises retrieval based on even those fields which are not indexed, as long as someone knows how to find what is being sought. The possibility of multiple call number indices can address the need for "virtual browsing" of closed stack collections, accommodating the local classification schemes that are often used for rare book collections. Davis' predictions of incompatible system requirements, duplication of work, and other problems associated with a lack of standardization among library systems appeared early on to be coming true, ${ }^{101}$ but the emergence of international standards for information exchange such as Z39.50 and other market factors have caused some resolution of these issues.

An important difference between manual and electronic files is the way in which computer systems read catalog records. For example, in filing cards, insertions such as "[sic]," or expansions of contracted words can be ignored, but these types of characters will affect retrieval in computer indexing. It becomes even more necessary, then, to provide additional forms of access based on the actual information transcribed as well as on the implied sense of that information. At the same time, it is possible to easily create headings for multiple interpretations of titles so that cataloger judgment, user knowledge, and even descriptive rules can be augmented with multiple search strings to retrieve records based on anachronistic spellings, expanded abbreviations, and the like.

In order to address some of these issues, the BSC led a study examining the expectations rare book catalogers had for their local systems. ${ }^{102}$ Results also appeared in the "Guide to Rare Book Records in Online Systems." 103 It outlines the minimal requirements on a local system for how it indexes, retrieves, and displays the type of information provided in rare book records. It is heartening to observe that many of these desiderata, which were uncommon or prohibitively expensive just a few years ago, are now becoming available in many cataloging systems. Because the market for library catalogs is rarely driven by small special-interest audiences, it is only now becoming possible to 
handle the information already provided for in USMARC, for example, with any degree of sophistication. ${ }^{104}$

Many of the objections raised in regards to bibliographic records for special collections materials are now, finally, being overcome. It is increasingly easy for anyone, not just a technologically savvy scholar, to search imprint fields, to gain access to the databases of OCLC and RLIN, and to manipulate data in catalogs without the need for complicated truncation strategies or delimiters required in years past. ${ }^{105}$ Nonetheless, it is important to continually keep in mind the limitations of rare book cataloging, even in the most sophisticated environment, particularly as the quality and consistency of any computer system still depends on the information provided by a human being.

The issue of retrospective conversion of rare book records, although not strictly related to codes and practices, does merit at least a brief mention because of its influence on the number, quality and character of bibliographic records for special collections material over the past several decades. Guidelines for the retrospective conversion of rare books catalogs, desired by some, ${ }^{106}$ did not materialize, with the result that many libraries found themselves "reinventing the wheel" when it came time to face the issue. One response to this situation indicates that retrospective conversion and the cleanup necessitated by it will continue to be a challenge for libraries for quite some time. ${ }^{107}$ This limitation must be borne in mind when formulating procedures for the use of descriptive rules since it is likely that earlier rules led to the construction of records in different ways than would current rules.

\section{CONCLUSION}

The creation of bibliographic records for rare books has a rich tradition and heritage, encompassing masterpieces of description and access that have served scholars well for generations. While this tradition has, in some ways, existed outside the mainstream of library cataloging, descriptive codes have come to acknowledge some of the special issues present in rare book cataloging, at least bringing them to the attention of generalist catalogers. While the impossibility of a single AngloAmerican cataloging code for all formats of information has been acknowledged, the continuing evolution of rare book codes has provided, in some ways, "one-stop shopping" for description and access.

At the same time, modern information technology offers amazing possibilities, such as linking bibliographic records to digital images of title pages and the simultaneous indexing of unlimited fields of information. Such possibilities are tempered by reality of costs, the need to handle large volumes of materials, and often a cooperative environment within or external to the library that imposes its own requirements. Nonetheless, the integration of rare book records into online catalogs for larger library collections has provided a degree of visibility, accountability, and cooperation unheard of in the early part of the twentieth century, when rare book cataloging practices were inherently localized. In this way, Anglo-American rare book cataloging has become an acknowledged part of the cataloging mainstream while maintaining its own conventions and purposes.

\section{ABBREVIATIONS}

$A A C R 1$

$A A C R 2$

$A A C R 2 R$
Anglo-American Cataloging Rules (North American Text). 1967.

Anglo-American Cataloguing Rules, 2nd ed. 1978.

Anglo-American Cataloguing Rules, 2nd ed., 1988 revision, amended 1993. 
BDRB Bibliographic Description of Rare Books: Rules Formulated Under AACR2 and ISBD(A) for the Descriptive Cataloging of Rare Books and Other Special Printed Materials.

BSC Bibliographic Standards Committee (Rare Books and Manuscripts Section/Association of College \& Research Libraries).

DCRB Descriptive Cataloging of Rare Books (DCRB), 2nd ed.

IFLA International Federation of Library Associations.

ISBD $(A) \quad \operatorname{ISBD}(A):$ International Standard Bibliographic Description for Older Monographic Publications (Antiquarian).

$\operatorname{ISBD}(M) \quad \operatorname{ISBD}(M)$ : International Standard Bibliographic Description for Monographic Publications.

\section{NOTES}

1. Paul Shaner Dunkin, How to Catalog a Rare Book (Chicago: American Library Association, 1951), 1.

2. For example: Ingrid Parent, "Building Upon Principles; Building Upon Success," International Cataloguing and Bibliographic Control 29, no. 1 (2000): 9-12.

3. Susan A. Adkins, "Automated Cataloging of Rare Books: A Time for Implementation," Collection Management 16, no. 1 (1992): 89-94. 55.

4. G. Thomas Tanselle, "Descriptive Bibliography and Library Cataloguing," Studies in Bibliography 30 (1977):

5. Laura Stalker and Jackie Dooley, "Descriptive Cataloging and Rare Books," Rare Books \& Manuscripts

Librarianship 7, no. 1 (1992): 9.

6. Ibid., 10.

7. James Westfall Thompson, The Medieval Library (Chicago: University of Chicago Press, 1939), 611.

8. Beth M. Russell, "Hidden Wisdom and Unseen Treasure: Revisiting Cataloging in Medieval Libraries." Cataloging \& Classification Quarterly 26, no. 3 (1998): 21-30.

9. Stalker and Dooley: 11.

10. G. Thomas Tanselle, "Title-page Transcription and Signature Collation Reconsidered," Studies in Bibliography 38 (1985): 45-81.

11. John Carter, ABC for Book Collectors, 7th ed. (New Castle, DE: Oak Knoll Books, 1995), 193.

12. Ibid., 106.

13. Ibid., 171.

14. Stephen Paul Davis, "Bibliographic Control of Special Collections: Issues and Trends," Library Trends 36, no. 1 (1987): 115.

15. Tanselle, "Descriptive Bibliography," 1-3.

16. Ibid., 4-5.

17. Ibid., 11.

18. Ibid., 14.

19.Ibid., 36-43.

20.Ibid., 45-46.

21.Ibid., 54.

22.Michael Winship, "What the Bibliographer Says to the Cataloger," Rare Books \& Manuscripts Librarianship 7, no. 2 (1992): 102.

23.John B. Thomas, III, "The Necessity of Standards in an Automated Environment, Library

Trends 36, no. 1 (1987): 129-130.

24. Dunkin, 82.

25. Paul Shaner Dunkin. How to Catalog a Rare Book, 2nd ed. (Chicago: American Library Association, 1973).

26. Fredson Bowers, Principles of Bibliographic Description (Princeton, N.J.: Princeton University Press, 1949).

27. Dunkin, 2nd ed., 92.

28. Ibid., ix.

29. Ibid., 36-39.

30. Ibid., 100.

31. Anglo-American Cataloging Rules (North American Text) (Chicago: American Library Association, 1967).

32. AACR1, 2-4.

33. Ibid., 191. 
34. Tanselle, "Descriptive Bibliography," 18-19.

35. Ibid., 19-24.

36. Carter, 125.

37. Josiah Q. Bennett, The Cataloguing Requirements of the Book Division of a Rare Book Library (Kent, Ohio:

Kent State University Libraries, 1969).

38. Ibid., 11.

39. Ibid., 10.

40. Ibid., 15-16.

41. Ibid., 18.

42. Ibid., 19.

43. Anglo-American Cataloguing Rules, 2nd ed. (Chicago: American Library Association, 1978).

44. ISBD(A): International Standard Bibliographic Description for Older Monographic Publications (Antiquarian)

(London: International Federation of Library Associations and Institutions, 1980).

45. ISBD $(M)$ : International Standard Bibliographic Description for Monographic Publications (London: IFLA, 1974), 1.

46. $\operatorname{ISBD}(A)$, vii.

47. Ibid., viii-ix.

48. Bibliographic Description of Rare Books: Rules Formulated Under AACR2 and ISBD(A) for the Descriptive

Cataloging of Rare Books and Other Special Printed Materials (Washington, D.C.: Library of Congress Office, 1981).

49. Ibid., [v].

50. Thomas asserts that ESTC cataloging practice, although not generally applicable to other institutions or projects,

developed as it did due to the lack of a cooperative code: 131.

51. $B D R B,[\mathrm{v}]-\mathrm{vi}$.

52. Ibid., 49.

53. Philip Gaskell, A New Introduction to Bibliography (New York: Oxford, 1972).

54. $B D R B, 51-52$.

55. Peter M. VanWingen and Stephen Paul Davis, Standard Citation Forms for Published Bibliographies and

Catalogs Used in Rare Book Cataloging (Washington, D.C.: Library of Congress, 1982).

56. G. Thomas Tanselle, "The Bibliographical Concepts of Issue and State," Papers of the Bibliographical Society of America 69 (1975): 17-66.

57. David M. Rich, Index to Bibliographical Description of Rare Books (Providence, R.I.: John Carter Brown

Library, 1987).

58. Thomas, 132.

59. Elisabeth W. Betz, Graphic Materials: Rules for Describing Original Items and Historical Collections (Washington,

D.C.: Library of Congress, 1982).

60. Steven L. Hensen, Archives, Personal Papers, and Manuscripts: A Cataloging Manual for Archival Repositories,

Historical Societies, and Manuscript Libraries. (Washington, D.C.: Library of Congress, 1983).

61. "Rare Serials," Cataloging Service Bulletin 26 (Fall 1984): 21-25.

62. Anglo-American Cataloguing Rules, 2nd ed., 1988 revision (Chicago: ALA, 1988, amended 1993).

63. ISBD(A): International Standard Bibliographic Description for Older Monographic Publications (Antiquarian),

2nd ed. (New York: Saur, 1991).

64. Ibid., xii.

65. Descriptive Cataloging of Rare Books (DCRB), 2nd ed. (Washington, D.C.: Cataloging Distribution Service,

Library of Congress, 1991).

66. Stalker and Dooley, 8.

67. $D C R B$, v.

68. Stalker and Dooley, 9-10.

69. $D C R B$, viii.

70. Stalker and Dooley, 11-13.

71. $D C R B$, viii.

72. Stalker and Dooley, 15.

73. $D C R B, 67-68$.

74. Ibid., 71.

75. Ibid., xii-xiii.

76. See, for example, BSC's "Rare Materials Cataloger's HelpNet," available on the World Wide Web (http://www.library.yale.edu/bibstand/resource.html) [cited 22 March 2002]. 
77. DCRB, 77.

78. Examples to Accompany Descriptive Cataloging of Rare Books (Chicago: Association of Research Libraries, 1993).

79. Ibid., iii-v.

80. "Core Standard for Rare Books (DCRB Core)," available on the World Wide Web: (http://lcweb.loc.gov/catdir/pcc/dcrbcore.html) [cited 19 March 2002].

81. Melissa C. Flannery, "A Review of Recent Developments in Rare Books Cataloging," Cataloging \& Classification Quarterly 7, no.1 (1986): 59.

82. The RBMS Bibliographic Standards Committee Revision Homepage chronicles the development of the project. Available on the World Wide Web: (http:// www.folger.edu/bsc/dcrb/dcrbrev.html) [cited 19 March 2002].

83. Bennett, 38-39.

84. For a discussion of the development of changes to the MARC format related to these fields, see Thomas, 132-138.

85. Binding Terms: A Thesaurus for Use in Rare Book and Special Collections Cataloguing (Chicago: Association of College \& Research Libraries, 1988).

86. Ibid., v.

87. Genre Terms: A Thesaurus for Use in Rare Book and Special Collections Cataloguing (Chicago: ACRL, 1983).

88. Ibid., i.

89. Ibid., iii.

90. Genre terms: A Thesaurus for Use in Rare Book and Special Collections Cataloguing, 2nd ed. (Chicago: ACRL, 1991).

91. Printing and Publishing Evidence: Thesauri for Use in Rare Book and Special Collections Cataloguing (Chicago: ACRL, 1986).

92. Provenance Evidence: A Thesaurus for Use in Rare Book and Special Collections Cataloguing (Chicago: ACRL, 1988).

93. Paper Terms: A Thesaurus for Use in Rare Book and Special Collections Cataloguing (Chicago: ACRL, 1990).

94. Type Evidence: A Thesaurus for Use in Rare Book and Special Collections Cataloging (Chicago: ACRL, 1990).

95. "RBMS Thesauri for Use in Rare Book and Special Collections Cataloging," available on the World Wide Web: (http://libweb.uoregon.edu/catdept/home/genreterms/ main.html) [cited 19 March 2002].

96. Art \& Architecture Thesaurus, available on the World Wide Web: (http://www.getty.edu/research/tools/vocabulary/aat/) [cited 22 March 2002].

97. Thomas, 129.

98. "BSC Relator Terms," available on the World Wide Web: (http://www.folger.edu/bsc/relators.html) [cited 19 March 2002].

99. "MARC 21 Code List for Relators, Sources, Description Conventions," available on the World Wide Web: (http://lcweb.loc.gov/marc/relators/) [cited 19 March 2002].

100. Bennett, 15.

101. Davis, 117.

102. Henry Raine and Laura Stalker, "Rare Book Records in Online Systems," Rare Book and Manuscript Librarianship 11, no. 2 (1996):103-118.

103. Available on the World Wide Web (http://www.folger.edu/bsc/guide.html) [cited 19 March 2002].

104. Adkins, 89-102. Adkins, although enthusiastic about the possibilities of automated rare book cataloging, was still realistic about the limitations on technology in the early 1990s. Many of these limitations no longer apply.

105. Winship, 102-105.

106. Davis, 116.

107."Summary Results of the Retrospective Conversion Survey of Rare Materials," available on the World Wide Web: (http://www.library.yale.edu/bibstand/survey98.htm) [cited 22 March 2002]. 